\title{
Desenvolvimento de filmes poliméricos ultrafinos e reticulados para aplicações em sensores
}

\section{Development of stable polymeric cross-linked ultrathin films for sensor applications}

\author{
Eliton Souto de Medeiros ${ }^{1 *}$, Rodrigo Andrade Martinez², Rubens Bernardes Filho ${ }^{3}$, Rinaldo Gregório Filho² e \\ Luiz Henrique Capparelli Mattoso ${ }^{3}$ \\ 'Departamento de Engenharia de Materiais, Universidade Federal da Paraíba, João Pessoa, PB, Brasil \\ ${ }^{2}$ Departamento de Engenharia de Materiais, Universidade Federal de São Carlos - UFSCar, \\ São Carlos, SP, Brasil \\ ${ }^{3}$ Embrapa Instrumentação Agropecuária, São Carlos, SP, Brasil \\ *eliton@ct.ufpb.br; elitonsdemedeiros@gmail.com
}

\begin{abstract}
Resumo
Este trabalho propõe um novo método de produção de filmes estáveis para aplicações em sensores baseado na deposição pela técnica de automontagem de poli(o-etoxianilina) alternada com fenol-formaldeído (POEA/PF) seguida por cura térmica. O processo de reticulação foi caracterizado por espectroscopias no infravermelho por transformada de Fourier e no ultravioleta-visível, microscopia de força atômica e estudos de dessorção; a capacidade sensorial destes filmes foi avaliada através de medidas em sensores. Os resultados mostram que a resina PF serviu como agente de cura e alternante formando uma rede semi-interpenetrante, por conseguinte, filmes mais estáveis foram produzidos. Embora tenha ocorrido uma diminuição da sensibilidade dos sensores com o reticulação, tais filmes são bastante estáveis e podem ser potencialmente usados em sensores, especialmente onde uma maior estabilidade se faz necessária.
\end{abstract}

Palavras-chave: sensores, polimeros condutores, filmes finos.

\section{Abstract}

A new method for producing stable films used in sensors is proposed, based on the layer-by-layer deposition of poly(o-ethoxyaniline) and phenol-formaldehyde (POEA/PF) followed by a thermal treatment to promote film crosslinking. The crosslinking process was characterized by Fourier transform infrared and ultraviolet-visible spectroscopic analyses, atomic force microscopy and desorption studies. Sensor analyses were also carried out in order to evaluate cross-linked sensor signal. Results showed that PF resin served as a curing agent, forming a semi-interpenetrating polymer network therefore producing stable films. Although there was a decrease in the sensitivity of sensors with crosslinking, such films are quite stable and can be potentially used in sensors, especially where higher stability is required.

Keywords: conductive polymers, sensors, ultrathin films.

\section{Introdução}

Sensores químicos usando filmes poliméricos ultrafinos têm recebido grande atenção nos últimos anos devido ao seu baixo custo relativo, possibilidade de miniaturização e diversidade de aplicações, tais como detecção de acidez em frutas, controle de qualidade de alimentos e bebidas, além da possibilidade de ter suas propriedades projetadas em função das necessidades quanto à seletividade e sensibilidade pelo controle da formação do filme e incorporação de outros materiais sensoativos ${ }^{[1,2]}$. Entre as técnicas utilizadas para obtenção dos filmes ultrafinos, a automontagem oferece muitas vantagens tais como, independência da forma e do tamanho do substrato, o tempo de deposição independe do tamanho do substrato, não há necessidade de usar equipamentos em salas limpas e uma grande quantidade de materiais pode ser automontada ${ }^{[1]}$.

Como as propriedades sensoativas dos filmes ultrafinos dependem da rugosidade, porosidade e espessura é importante controlar tais características durante a produção do filme. Apesar de as propriedades sensoativas destes filmes permitirem largo espectro de aplicações, a perda de material durante o uso é um problema que limita a aplicabilidade e durabilidade de filmes ultrafinos como materiais sensoativos em sensores. Isto ocorre porque a dessorção do filme, para a solução em análise ou durante a limpeza dos sensores, é inerente ao processo de automontagem que se baseia principalmente em forças de atração eletrostática e ligações de hidrogênio 
que são ligações fracas ${ }^{[2,3]}$. Para solucionar este problema, alguns estudos foram realizados utilizando polímeros reticuláveis como o poli(álcool vinílico) ${ }^{[5]}$, poli(hidrocloreto de alilamina) $(\mathrm{PAH})$, poli(ácido acrílico) $(\mathrm{PAA})^{[4]} \mathrm{e}$ poliacrilamida (PAAm) $)^{[5]}$ e copolímeros de formaldeído e polianilina ${ }^{[6]}$ para melhorar a adesão e a coesão dos filmes. Por conseguinte, este trabalho propõe um novo método de produção de filmes estáveis baseado na deposição de poli(oetoxianilina) alternada com fenol-formaldeído (POEA/PF) seguida de cura a $150{ }^{\circ} \mathrm{C}$. O processo de reticulação foi caracterizado por espectroscopias no infravermelho por transformada de Fourier (FTIR) e no ultravioleta-visível (UV-Vis), microscopia de força atômica (AFM) e estudos de dessorção; a capacidade sensorial destes filmes foi avaliada através de medidas de sensores para concentrações de ácido cítrico de 0 a 1000 ppm.

\section{Experimental}

\subsection{Síntese do polímero}

A poli(o-etoxianilina) dopada com ácido canforsulfônico, POEA(CSA), foi sintetizada por polimerização interfacial. Este sistema consiste na síntese através da interface de um sistema bifásico (água e solvente orgânico), onde o monômero é dissolvido no solvente orgânico e o oxidante e dopante são dissolvidos em água. Apesar de ser um método usado há décadas na polimerização de poliamidas ${ }^{[6]}$, a polimerização interfacial tem sido muito recentemente na obtenção de micro e nanoestruturas de polímeros condutores ${ }^{[7,8]}$.

A o-etoxianilina (Sigma Aldrich, USA) dissolvida em 1,2 dicloroetano, DCE, (Mallinckrodt Baker, USA) foi usada como fase orgânica. O oxidante, persulfato de amônio, APS, (Merk, USA), e o dopante, ácido canforsulfônico (Sigma Aldrich, USA), dissolvidos em água ultra-pura (milli-Q) sob agitação por cerca de 20 minutos antes da síntese, foram usados como fase aquosa. A concentração de monômero e dopante (CSA) foi mantida em 1,0 M, e a relação monômero:oxidante foi fixa em 1:1. A síntese foi realizada a $(25 \pm 2)^{\circ} \mathrm{C}$ por $12 \mathrm{~h}$.

Devido à elevada solubilidade da POEA (CSA) em meio aquoso, durante a etapa inicial da polimerização cadeias em crescimento migram para a fase inorgânica, que é pobre em monômero, fazendo com que haja uma alta concentração de oligômeros no polímero final. Desta forma, o polímero foi lavado exaustivamente com acetona para remoção dos oligômeros até o filtrado se tornar incolor e seco sob vácuo por $24 \mathrm{~h}$.

\subsection{Preparação e reticulação dos filmes ultrafinos}

O polímero resultante, na forma dopada, foi dissolvido em álcool etílico comercial para formar uma solução $10^{-3} \mathrm{M}$, baseando-se na massa molar do tetrâmero dopado. A resina fenol-formaldeído (PF) do tipo novolaca (CR-4871, Crios Resinas Sintéticas Ltda., Rio Claro - SP), com teor de agente de cura (hexamina, HMTA) entre 6,5 e 7,0\%, foi dissolvida em álcool à concentração de $1 \mathrm{~g} / \mathrm{L}$ e usada na reticulação dos filmes.

Os substratos vidro ótico (BK7 Superwrite, Opto Eletrônica S.A.) de dimensões padronizadas $(30 \times 10 \times 1 \mathrm{~mm})$, usados para a deposição dos filmes, foram previamente lavados em solução piranha $\left(\mathrm{H}_{2} \mathrm{SO}_{4} / \mathrm{H}_{2} \mathrm{O}_{2}\right)$ na proporção volumétrica de 7:3 por uma hora em ultra-som, seguido por lavagem em água ultra pura. Posteriormente, estas lâminas foram mantidas em um banho de $\mathrm{H}_{2} \mathrm{O} / \mathrm{H}_{2} \mathrm{O}_{2} / \mathrm{NH}_{4} \mathrm{OH}$, na proporção volumétrica de $5: 1: 1$, a $80^{\circ} \mathrm{C}$ por 40 minutos e novamente lavadas exaustivamente em água ultra pura. Este tratamento tem por finalidade a limpeza do vidro para remover possíveis impurezas que influenciem o processo de adsorção dos filmes.

Os filmes foram depositados por automontagem nos substratos de vidro a partir das soluções poliméricas com $\mathrm{pH}$ ajustado para 3 e o tempo de imersão de 5 min. Entre cada imersão os filmes foram lavados em água ultra-pura de mesmo pH por 15 minutos. Estas condições foram estabelecidas a partir de estudos da cinética de deposição dos filmes que foi monitorada por UV-Vis no ponto isobéstico a $462 \mathrm{~nm}$ para tempos de deposição entre 0 e 30 min $^{[2]}$.

A reticulação dos filmes foi feita em forno por tempos de 2 a 8 minutos e temperatura de $150{ }^{\circ} \mathrm{C}$. Estes parâmetros foram baseados em estudo prévios da cinética de cura da resina PF por calorimetria exploratória diferencial (DSC) ${ }^{[9]}$.

\subsection{Caracterização dos filmes ultrafinos por microscopia de força atômica (AFM)}

As imagens de microscopia de força atômica foram obtidas em um microscópio Topometrix modelo Discoverer TMX 2010, em modo contato, utilizando um cantiléver com raio de ponta inferior a $20 \mathrm{~nm}$ e constante de mola de $0,6 \mathrm{Nm}$.

A metodologia de medida de espessura do filme consistiu em raspar cuidadosamente, com uma espátula, as camadas do filme para a formação de degraus que permitissem a avaliação dessa espessura. As medidas de curva de força (força $v s$. distância) foram realizadas para filmes curados e não curados através da indentação do filme com a ponta da agulha. A partir das curvas determinou-se o valor da inclinação da curva força versus distância para cada filme. Todas as medidas reportadas são valores médios de seis medidas.

\subsection{Caracterização da cura por espectroscopia no Infravermelho por Transformada de Fourier (FTIR)}

Os polímeros foram caracterizados por espectrometria no infravermelho por transformada de Fourier (FTIR) num espectrômetro 1000 da Perkin-Elmer na região espectral entre 4000 e $400 \mathrm{~cm}^{-1}$, resolução espectral de $4 \mathrm{~cm}^{-1}$ e 32 varreduras por espectro. As amostras foram preparadas usando pastilhas de $\mathrm{KBr}$ contendo cerca de $2 \%$ em peso dos polímeros que foram removidos de substratos contendo filmes automontados antes e depois do processo de cura.

\subsection{Caracterização por espectrometria no Ultravioleta- Visivel (UV-Vis)}

Os espectros de UV-Vis foram obtidos num espectrômetro da Shimadzu modelo UV 1601 PC numa faixa de comprimento de onda de 300 a $1100 \mathrm{~nm}$. As medidas foram realizadas diretamente nos filmes depositados sobre os substratos de vidro óptico. 


\subsection{Microscopia eletrônica de Varredura por Emissão de Campo (FESEM)}

Os polímeros sintetizados foram caracterizados por microscopia eletrônica de varredura por emissão campo (FESEM) num microscópio da marca Oxford modelo XL 30 (DEMa/UFSCar). Os polímeros na forma de pó foram pulverizados numa fita de carbono dupla-face e as micrografias foram obtidas nos diversos aumentos. A morfologia foi inspecionada em várias porções da amostra para que as micrografias obtidas fossem representativas da morfologia dessas amostras.

\subsection{Medidas de estabilidade dos filmes}

A estabilidade dos filmes foi avaliada através de sua cinética de dessorção (perda do filme para a solução de lavagem em função do tempo). Os filmes poliméricos depositados foram lavados em água destilada com velocidade de agitação de cerca de $400 \mathrm{rpm}$ (rotação aproximada da barra magnética) em intervalos de $30 \mathrm{~min}$. Cada placa de vidro ficou suspensa na vertical para permitir uma maior remoção do filme devido ao arraste da agitação. Após esse tempo, os filmes foram secos em nitrogênio e sua absorbância monitorada por UV-Vis no ponto isobéstico da POEA (CSA) em álcool, ou seja, a $462 \mathrm{~nm}^{[10]} \mathrm{em}$ função do tempo. Este estudo foi realizado em pH 7 para neutralizar as cargas dos polímeros e minimizar as interações eletrostáticas entre as camadas. A razão entre a absorbância inicial e a absorbância de equilíbrio $\left(\mathrm{A}_{0} / \mathrm{A}_{\infty}\right)$ fornece dados quantitativos para comparar a estabilidade dos filmes, ou seja, um filme estável é aquele que não sofre dessorção para a solução $\left(\mathrm{A}_{\infty} \rightarrow \mathrm{A}_{0}\right)$.

\subsection{Medidas de sensores}

Medidas de resistência ( $R$ ) foram realizadas num analisador de resposta em freqüência e fase da marca Solartron, modelo 1260, acoplado a um multiplexador de 10 ou 40 canais e um software dedicado a uma freqüência fixa de $1 \mathrm{kHz}$ e amplitude de sinal $\mathrm{AC}$ de $50 \mathrm{mV}$ a $25 \pm 1^{\circ} \mathrm{C}$ num banho termostático.

Os filmes ultrafinos foram depositados em microeletrodos interdigitados contendo 25 pares de dígito com $5 \mathrm{~mm}$ de comprimento, $10 \mu \mathrm{m}$ de largura, $10 \mu \mathrm{m}$ de espaçamento entre si e $0,1 \mu \mathrm{m}$ de espessura da camada de ouro depositada (vide Esquema 1). Este arranjo tem a seguinte configuração:

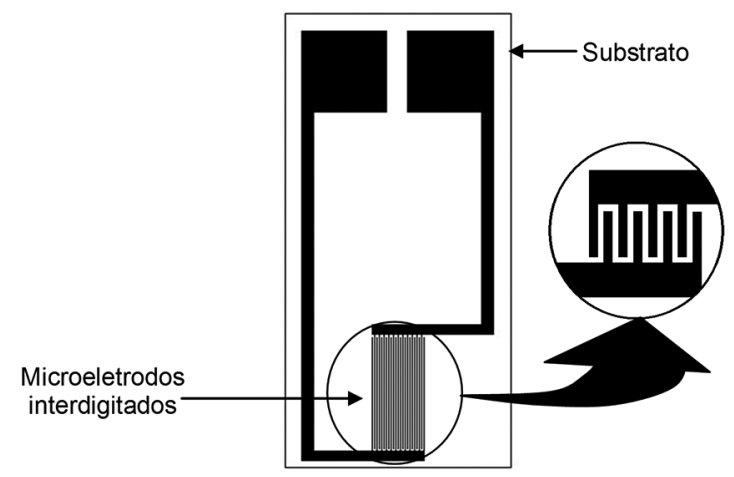

Esquema 1. Vista frontal esquemática dos microeletrodos interdigitados usados na fabricação dos sensores com detalhe mostrando a região dos dígitos.
Sensor 1. Eletrodo sem filme; Sensor $2-5$ bicamadas de POEA(CSA)/PF sem reticulação; Sensor 3.5 bicamadas de POEA(CSA)/PF com reticulação por 3 minutos a $150^{\circ} \mathrm{C}$ e Sensor 4.5 bicamadas de POEA(CSA)/PF com reticulação por 6 minutos a $150{ }^{\circ} \mathrm{C}$.

O ácido cítrico foi usado em concentrações variando de 0 a $1000 \mathrm{ppm}(\mathrm{m} / \mathrm{m})$ em água ultra-pura. As amostras foram analisadas em triplicatas e cada valor de R representado é uma média de 50 medidas depois de 5 min de estabilização do sensor. Nos experimentos dinâmicos a resistência (R) foi monitorada em função do tempo. A normalização dos dados foi realizada dividindo-se o valor da resistência de uma dada concentração do analito (R) pelo valor do branco (água) $\left(\mathrm{R}_{0}\right)$.

\section{Resultados e Discussão}

A POEA é um polímero derivado da polianilina (PAni) pela introdução do grupo alquila, cuja finalidade, entre outras, é o aumento na solubilidade ${ }^{[11,12]}$. A reduzida solubilidade dos polímeros condutores, especialmente no estado dopado, é um fator bastante crítico que limita o número de aplicações dos polímeros condutores. Por outro lado, a dopagem com ácidos protônicos funcionalizados como o canforsulfônico (CSA) tem sido usada como uma maneira alternativa de aumentar a solubilidade e condutividade dos polímeros no estado dopado ${ }^{[1,12]}$. Neste sentido, a POEA (CSA) obtida (as Figuras 1a e 1b mostram a morfologia deste polímero após a síntese) pode ser prontamente solúvel em vários solventes orgânicos (álcool etílico, acetona, N-metil-2-pirrolidona-NMP, tetrahidofurano - THF, etc.) e água. A solubilização da POEA (CSA) em álcool foi particularmente interessante neste estudo por ter possibilitado a automontagem de filmes ultrafinos alternados com a resina fenol-formaldeído (PF).

A Figura 2 mostra os espectros de FTIR para os polímeros antes e depois da cura. O estudo por FTIR foi feito para os componentes individuais (POEA e PF) e para a mistura (POEA + PF curada e não curada). Observa-se nesta figura que as principais mudanças ocorridas na região entre 600 e $1800 \mathrm{~cm}^{-1}$ são devidas à reticulação da resina $\mathrm{PF}{ }^{[9]}$, pois não há mudanças no espectro da POEA pura com mesmo tratamento térmico de cura da resina PF - espectros (e) e (f). As mudanças podem ser observadas apenas na cura da resina PF - espectros (a) e (b) - ou nos filmes de POEA/PF - espectros (c) e (d).

Nos espectros da Figura 2b, observa-se o aparecimento de uma nova absorção em $1650 \mathrm{~cm}^{-1}$, atribuída ao estiramento dos grupos carbonilas, como um ombro no dubleto a $1600 \mathrm{~cm}^{-1}$, devido à formação de benzofenona como conseqüência de reações de oxidação durante a cura. As intensidades relativas desse dubleto em 1612/1595 $\mathrm{cm}^{-1}$, relativo ao estiramento da ligação $\mathrm{C}=\mathrm{C}$ do anel aromático, se igualam em intensidade devido ao processo de reticulação ${ }^{[12-14]}$.

O pico a $1510 \mathrm{~cm}^{-1}$, relativo a o estiramento fora do plano de anéis aromáticos com substituições nas posições $1,2,4$, muda de intensidade, provavelmente, devido a outras substituições ${ }^{[12-14]}$.

A região entre 1400 e $1500 \mathrm{~cm}^{-1}$, relativa ao estiramento da ligação $\mathrm{C}-\mathrm{H}$ de $\mathrm{Ar}-\mathrm{CH}_{2}-\mathrm{Ar}$ (onde $\mathrm{Ar}=$ aromático) tem três picos com intensidades relativas diferentes em 


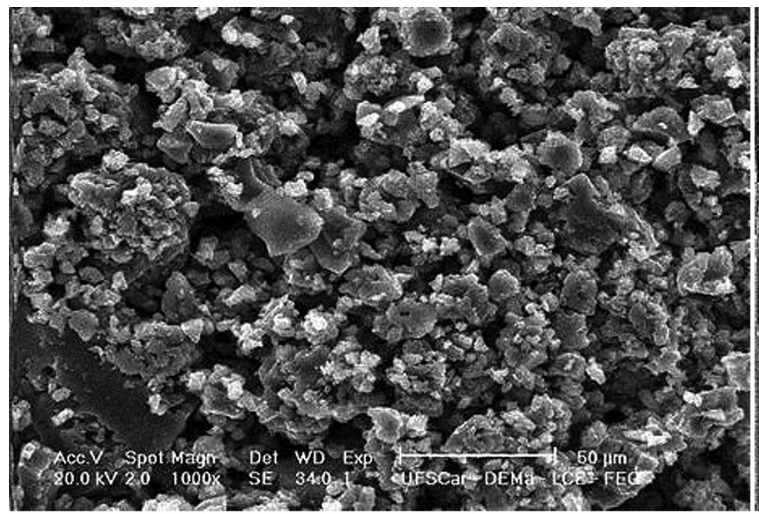

(a)

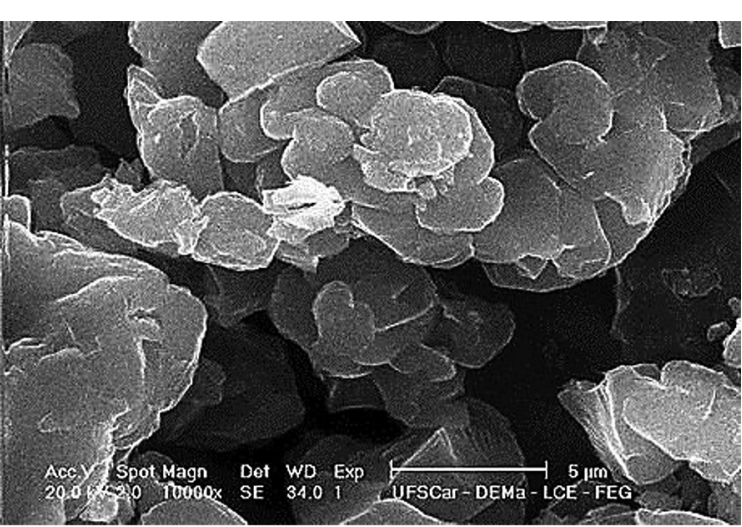

(b)

Figura 1. Micrografia de partículas de POEA (CSA) obtidas por síntese interfacial, mostrando a sua (a) morfologia particulada e (b) detalhe das partículas.

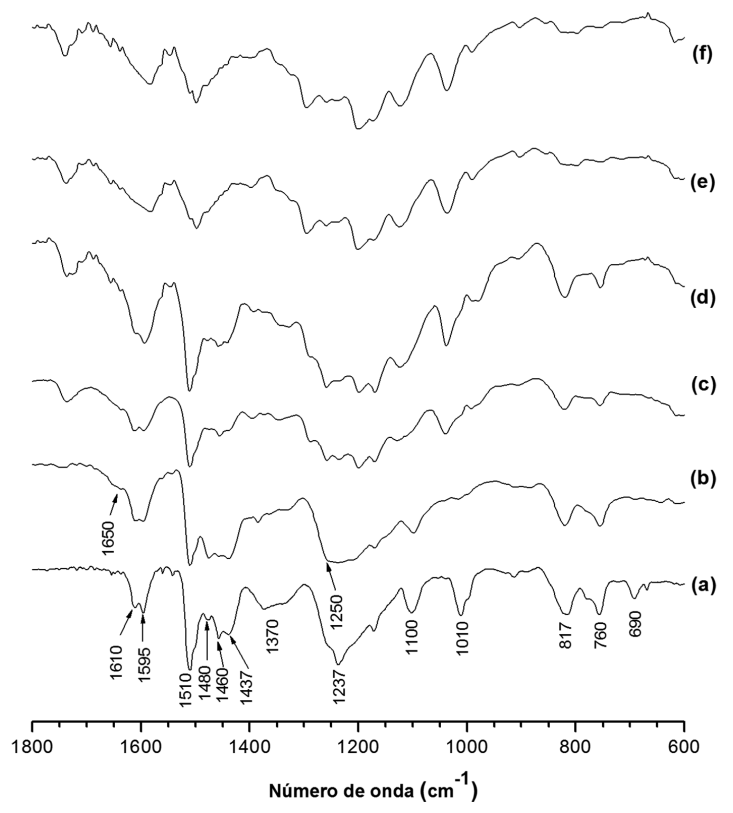

Figura 2. Espectros de transmissão por FTIR da: (a) PF não curada; (b) PF curada; (c) POEA+PF curada; (d) POEA+PF não curada; (e) POEA não submetida ao mesmo tratamento térmico de cura da resina PF e (f) POEA submetida ao tratamento térmico de cura.

1480, 1460 e $1437 \mathrm{~cm}^{-1}$, atribuídos, respectivamente, à formação de pontes metilênicas $\left(-\mathrm{CH}_{2}-\right)$ nas posições o-p', o-o' e p-p' dos anéis benzênicos. Essas intensidades relativas mudam com o processo de cura, permanecendo na mesma ordem o que indica que um número equiprovável de substituições ocorreu nas posições orto, meta e para do anel aromático ${ }^{[12-14]}$.

A banda a $1370 \mathrm{~cm}^{-1}$, relativa ao estiramento da ligação -O-H, diminui em intensidade provavelmente devido a reações de condensação nos grupos $-\mathrm{OH}$ e à formação de uma rede tridimensional mais fechada - reticulado polimérico semi-interpenetrante (semi-IPN) - que contribui para uma maior dificuldade de estiramento desse grupo. A banda a $1250 \mathrm{~cm}^{-1}$, resultante da formação de éster, aparece na resina curada como um pequeno ombro junto à banda $\mathrm{a}$ $1237 \mathrm{~cm}^{-1[12-16]}$.

As bandas de absorção a 1237 e $1170 \mathrm{~cm}^{-1}$, referentes ao estiramento da ligação C-O de alquil-fenol (metilol), e a banda em $1100 \mathrm{~cm}^{-1}$ referente à deformação (no plano) de $\mathrm{C}-\mathrm{H}$ do anel aromático, diminuem de intensidade com o processo de cura ${ }^{[12-16]}$.

A banda a $1010 \mathrm{~cm}^{-1}$, referente à deformação da ligação C-N do hexametilenotetramina (HMTA), desaparece quase que completamente. Durante o processo de cura, o HMTA se decompõe em amônia e formaldeído, a amônia age como catalisador para a reticulação, sendo volatilizada subseqüentemente, enquanto que o formaldeído atua como o agente de cura transformando-se em pontes metilênicas que ligam os fenóis para formar uma rede tridimensional de fenol e formaldeído, ou seja, a resina PF ${ }^{[14,15]}$.

As bandas de absorção a 817 e $760 \mathrm{~cm}^{-1}$, referentes às deformações das ligações $\mathrm{C}$-H fora do plano devidos a substituições 1,2 - 1,2,6 (orto) e 1,4-1,2,4 (para) do anel benzênico, são apresentadas pela resina curada e não curada. A resina não curada encontra-se na forma de um pré-polímero que exibe as mesmas substituições do polímero completamente reticulado, a diferença essencial é que as cadeias são predominantemente lineares e curtas (baixa massa molar), enquanto que no polímero reticulado essas moléculas reagem entre si para formar uma rede tridimensiona ${ }^{[14,15]}$. A banda a $690 \mathrm{~cm}^{-1}$, referente a deformações da ligação C-H fora do plano de anel benzênico mono-substituído (predominância de cadeias lineares) desaparece para a resina curada devido a substituições nas posições orto, meta e para, mencionadas anteriormente. Os espectros nos itens (d) a (f) são mostrados para fins comparativos, mostrando que as mudanças nos picos não são devidas à POEA, mas sim à reticulação da resina $\mathrm{PF}$.

As absorções no UV-Vis características da POEA antes e após tratamento térmico de cura da resina PF são mostradas na Figura 3. Esta figura mostra que as absorções no UV-Vis características da POEA são mantidas após tratamento térmico. Entretanto, é observada uma mudança na intensidade e na 


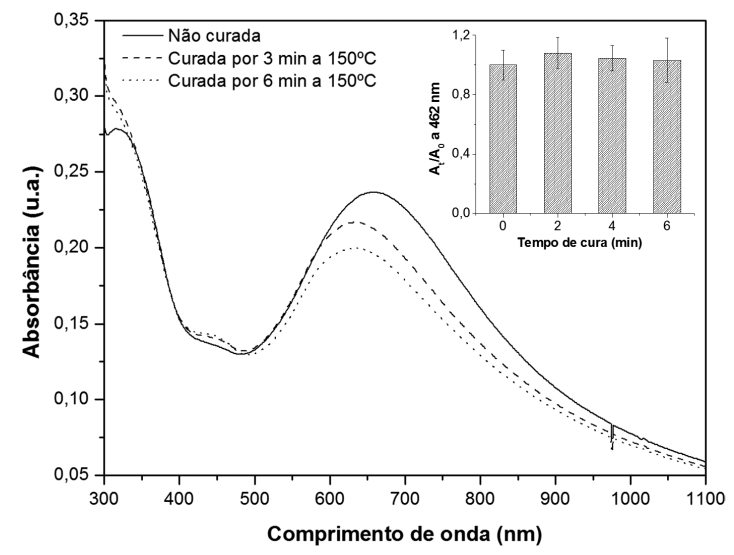

Figura 3. Espectros de absorção no UV-Vis para filmes de 15 bicamadas de POEA (CSA)/PF não curados e curados por 3 e 6 minutos a $150{ }^{\circ} \mathrm{C}$ e absorbância (normalizada) no ponto isobéstico em função do tempo de cura (parte superior direita do gráfico).

posição da banda polarônica com o tempo de cura devido à liberação de amônia como um subproduto da cura da resina $\mathrm{PF}^{[9]}$ que interage com os filmes desdopando-os. A figura na (parte superior direita) mostra que não houve perdas significativas de filme durante o processo de reticulação, uma vez que a absorbância a $462 \mathrm{~nm}$ não varia significantemente com o tempo de cura. A absorbância no ponto isobéstico está relacionada à espessura do filme depositado sobre o substrato ${ }^{[16]}$.

A caracterização por AFM mostra que os filmes sofreram mudanças morfológicas com o processo de reticulação, medidas através da espessura e da rugosidade, conforme se observa na Figura 4. A parte superior dessa figura exibe detalhe do degrau formado no filme para determinação da espessura e na parte inferior a análise de linha mostrando a variação na espessura dos filmes.

As imagens apresentadas nas Figuras 3a e 1b mostram que a espessura do filme decresceu com a cura de $86,8 \pm 8,1$ para 55,9 $\pm 5,2 \mathrm{~nm}$. O mesmo comportamento foi observado na medida da rugosidade média que passou de $24,4 \pm 0,3$ para $14,8 \pm 0,8 \mathrm{~nm}$. Essa alteração da rugosidade e da espessura do filme é conseqüência de dois fatores: perda de água e álcool etílico que permanecem entre as camadas durante o processo de deposição e da liberação de subprodutos da cura que são normalmente seguidos por uma reacomodação das cadeias nas camadas de modo a torná-las mais empacotadas; conseqüentemente, o filme torna-se menos espesso e menos $\operatorname{rugoso}^{[17]}$.

Os testes de adesão feitos com AFM (vide Figura 4) indicaram que a resistência mecânica do filme aumentou com o processo de cura, isto foi observado pela alteração da inclinação da curva de aproximação entre o cantiléver e o filme, na região entre 225 e $150 \mathrm{~nm}$. Para o filme não curado (Figura 5) foi observada alteração contínua na inclinação da curva de aproximação indicando que ocorre uma deformação plástica contínua neste com a aproximação do cantiléver (processo de nanoindentação); enquanto que para o filme curado, há uma mudança abrupta de inclinação devido à formação de uma superfície mais rígida em conseqüência do processo de cura.

Este comportamento também se reflete no valor da inclinação da curva entre 150 e $225 \mathrm{~nm}$, relacionada com a rigidez do filme, que mudou de $-(19.1 \pm 0.2) \times 10^{-4}$ para $-(28.9 \pm 0.1) \times 10^{-4} \mathrm{nN} / \mathrm{nm}$ com a cura do filme, indicando que houve um aumento na rigidez (e na coesão do filme) ${ }^{[17]}$. A inclinação entre 0 e $100 \mathrm{~nm}$, referente à deformação da agulha após o seu contato com a superfície do vidro, permaneceu sem alterações em ambas curvas de força, como era de se esperar uma vez que a agulha é a mesma. Quanto à adesão, pode-se observar pequeno aumento da força de adesão entre o cantiléver e o filme curado. Essas mudanças na adesão, rugosidade e rigidez causaram um aumento na estabilidade dos filmes curado embora também tenha causado também uma diminuição na sua sensibilidade, conforme será mostrado a seguir.

A Figura 6 mostra a dessorção dos filmes curados e não curados. O estudo de dessorção feito em água mostra que não houve dessorção significativa pra os filmes curados, enquanto que uma leve perda de filme ocorreu para os não curados.

Os prováveis fatores que podem ter contribuído para este comportamento são: a alta adesividade da resina PF, sua interação forte com a POEA (mistura desses dois polímeros em solução precipitam rapidamente, indicando a sua capacidade de formação de complexo) e a formação de camadas SEMI-interpenetrantes ${ }^{[18]}$. Ou seja, a estabilidade dos filmes é atribuída a sua estrutura tridimensional com ligações primárias (covalentes) formando um reticulado polimérico semi-interpenetrante (semi-IPN). A Figura 7 mostra esquematicamente o modelo de cura proposto.

O arranjo de sensores, construído conforme descrito na seção experimental, foi usado para medidas de ácido cítrico em diferentes concentrações. Este ácido foi escolhido para desenvolver um arranjo de sensores usados como língua eletrônica para sucos de laranja ${ }^{[10]}$, em combinação com outros polímeros.

A resistência normalizada $\left(R / R_{0}\right)$ em função da concentração de ácido cítrico é mostrada na Figura 8. Estes resultados mostram que o eletrodo sem filme é mais sensível a variações na concentração de ácido cítrico do que os sensores com filmes curado e não curado, embora a reprodutibilidade e a regularidade da resposta do sensor sem filme seja baixa quando comparada com sensores com filmes ${ }^{[10,19]}$. Além disso, observa-se que a sensibilidade da reposta (inclinação da curva de $\mathrm{R} / \mathrm{R}_{0}$ versus concentração de ácido cítrico) depende do grau de reticulação, ou seja, há uma diminuição da sensibilidade com o grau de reticulação.

Este comportamento na Figura 8 é devido ao aumento na dificuldade de dopagem e desdopagem do filme no qual a rede tridimensional de ligações cruzadas é uma barreira para a difusão (do filme para a solução e vice versa) tanto do analito quanto do contra-íon dopante afetando, portanto, o processo de transdução de sinal. Além disso, a diminuição da área de contato do filme pelo analito, conforme verificado por AFM através da diminuição na rugosidade, é um outro fator que contribui para esta diminuição na sensibilidade dos filmes. 

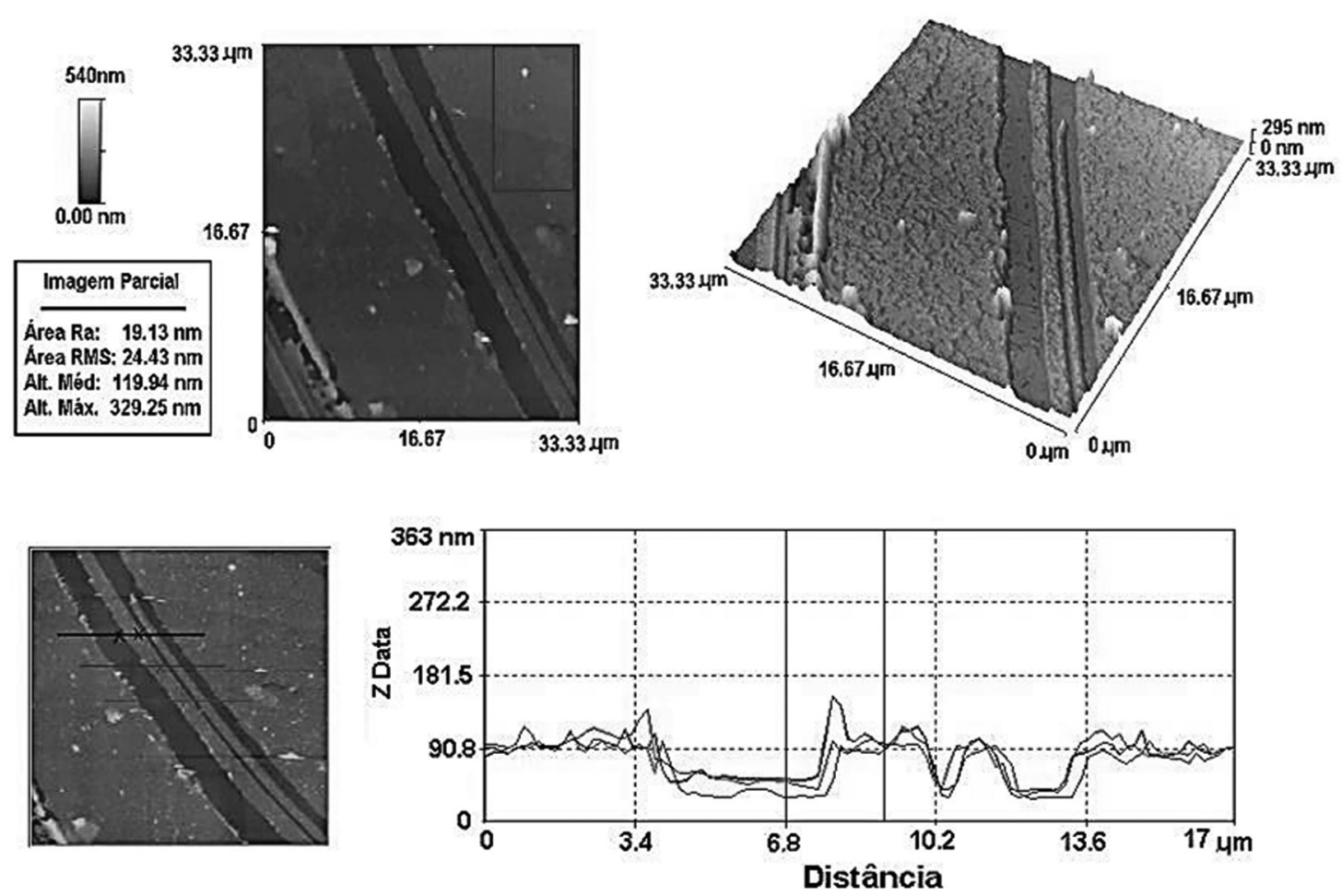

(a)
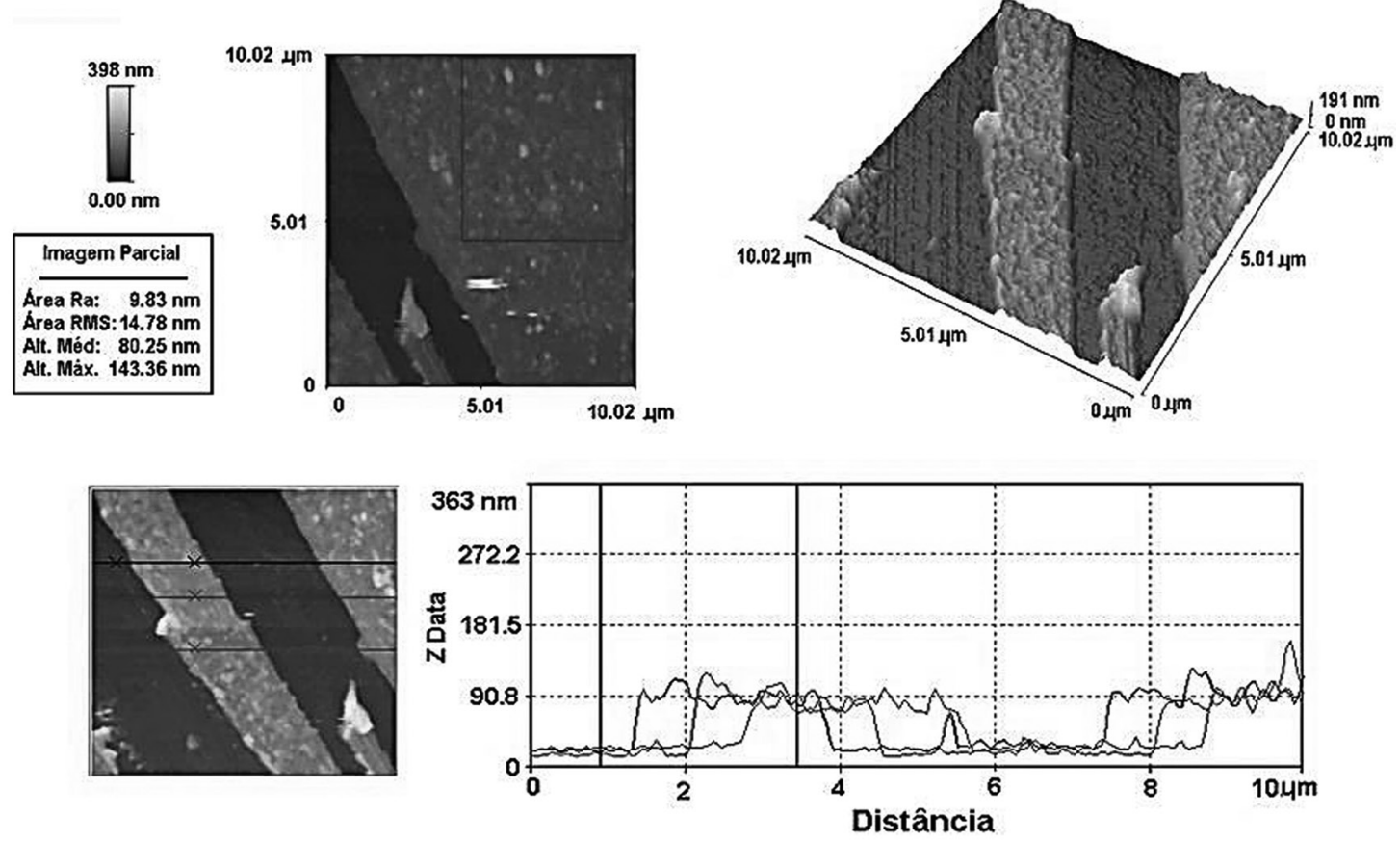

(b)

Figura 4. Imagens de AFM e perfil da sua altura mostrando as mudanças na espessura e na rugosidade de filmes de POEA (CSA)/PF com 15 bicamadas: (a) filme não curado; (b) filme curado. 


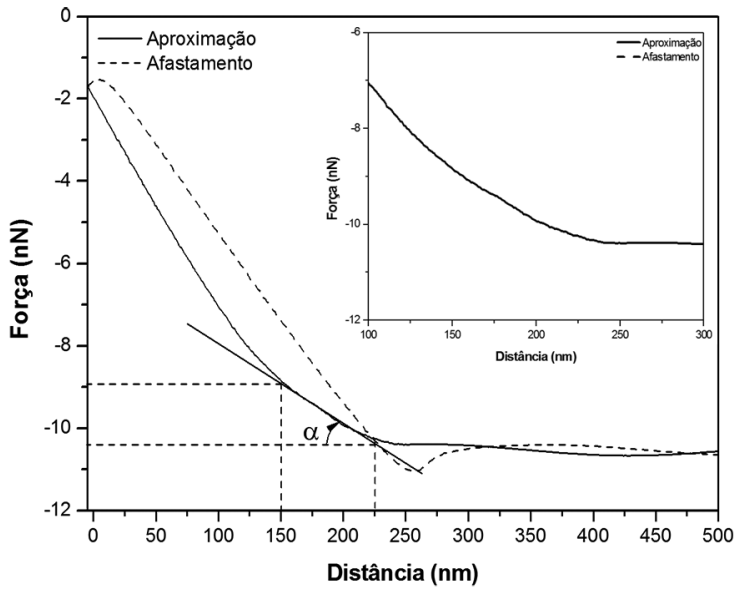

(a)

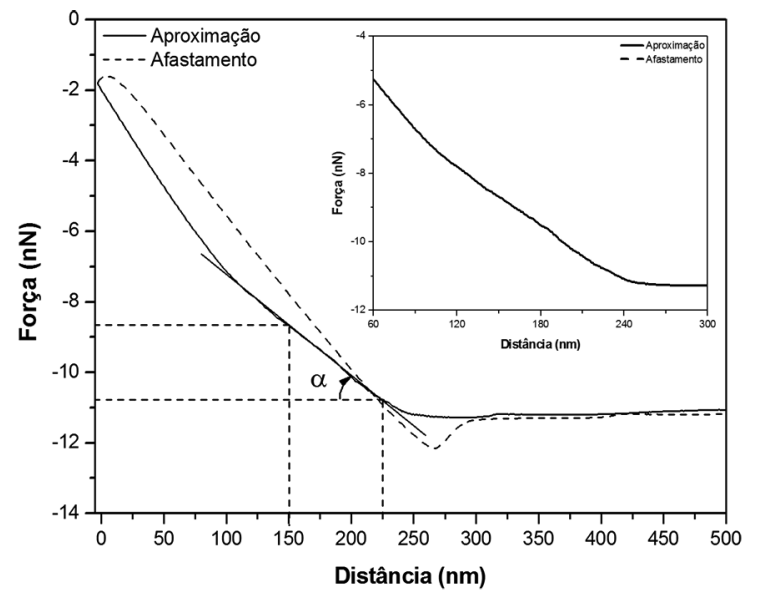

(b)

Figura 5. Curvas força vs. distância, obtidas por microscopia de força atômica: (a) amostra não curada de filme de POEA/PF e (b) filme de POEA/PF curado por 3 minutos a $150^{\circ} \mathrm{C}$. Parte superior direita: detalhe da mudança de inclinação das curvas.

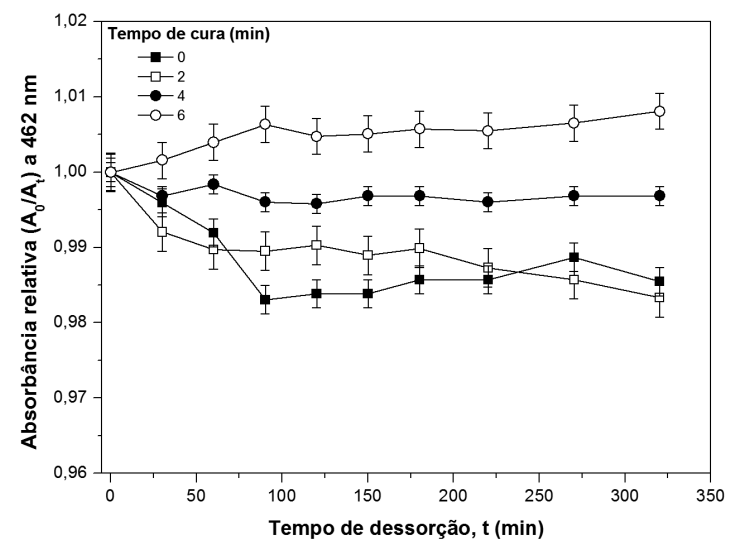

Figura 6. Curvas de dessorção em água dos filmes de POEA/PF com 15 bicamadas, curados a $150{ }^{\circ} \mathrm{C}$ por tempos de 2 a 6 min.

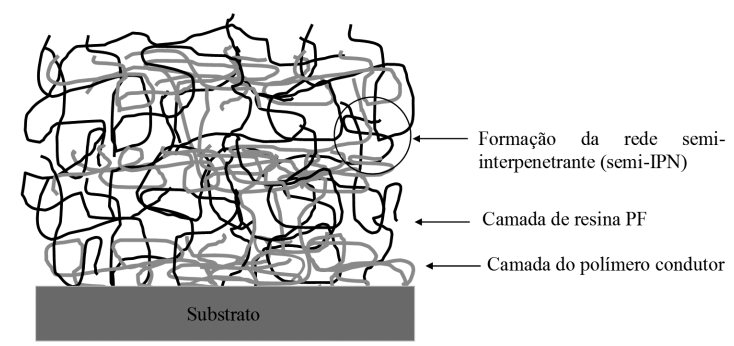

Figura 7. Esquema ilustrativo da cura do filme multicamadas alternadas de POEA/PF com a formação de uma rede tridimensional semi-interpenetrante (semi-IPN).

Mesmo assim, os sensores contendo filmes são sensíveis a variações na concentração de ácido cítrico, sem nenhuma diferença significativa até 100 ppm, mostrando, portanto, que os filmes reticulados podem ser potencialmente usados em sensores, especialmente onde a estabilidade se faz necessária. Além disso, estes filmes podem ser usados como suporte

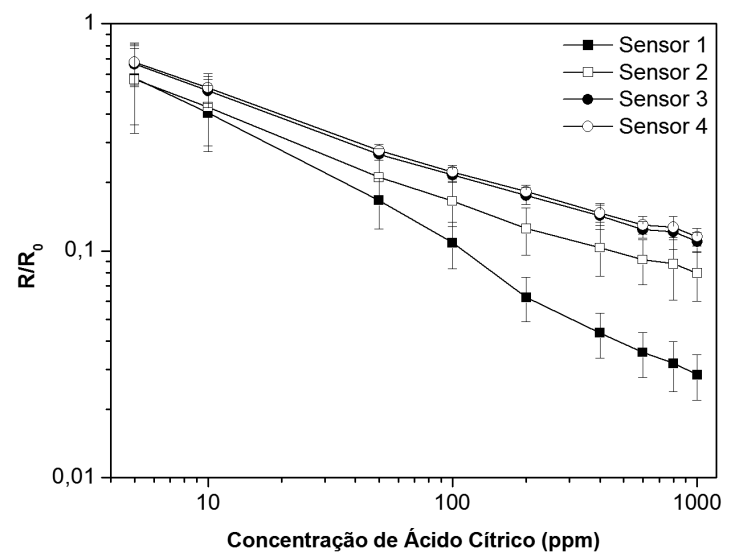

Figura 8. Resistência normalizada $\left(R / R_{0}\right)$ em função da concentração de ácido cítrico. Sensor 1 - eletrodo sem filme; Sensor $2-5$ bicamadas de POEA (CSA)/PF sem reticulação; Sensor 3 - 5 bicamadas de POEA (CSA)/PF com reticulação por 3 minutos a $150^{\circ} \mathrm{C}$ e Sensor $4-5$ bicamadas de POEA(CSA)/PF com reticulação por 6 minutos a $150{ }^{\circ} \mathrm{C}$.

na imobilização de outras moléculas capazes de aumentar a seletividade sensibilidade do sensor ${ }^{[1]}$.

\section{Conclusões}

Filmes curados de POEA/PF foram produzidos pela técnica de automontagem onde a resina PF serviu como agente de cura e alternante formando uma rede semi-interpenetrante. A caracterização dos filmes por FTIR, AFM, UV-Vis, medidas de dessorção e de sensores mostram que o processo de cura torna os filmes mais estáveis. Embora haja uma leve diminuição na sua sensibilidade na detecção do ácido cítrico, estes filmes são estáveis e podem ser potencialmente usados como materiais sensoativos em sensores, especialmente onde uma maior estabilidade ao longo do tempo se faz necessária. 


\section{Referências}

1. Grimes, C. A., Dickey, E. C., \& Pishko, M. V. (2006). Encyclopedia of sensors. Stevenson Ranch: American Scientific Publishers.

2. Cheung, J. H., Stockton, W. B., \& Rubner, M. F. (1997). Molecular-level processing of conjugated polymers. 3 . layer-by-layer manipulation of polyaniline via electrostatic interactions. Macromolecules, 30(9), 2712-2716. http://dx.doi org/10.1021/ma970047d.

3. Decher, G. (1997). Fuzzy nanoassemblies: toward layered polymeric multicomposites. Science, 277(5330), 1232-1237. http://dx.doi.org/10.1126/science.277.5330.1232.

4. Gangopadhyay, R., \& De, A. (2002). Conducting semi-IPN based on polyaniline and crosslinked poly(vinyl alcohol). Synthetic Metals, 132(1), 21-28. http://dx.doi.org/10.1016/ S0379-6779(02)00212-6.

5. Yang, S. Y., \& Rubner, M. F. (2002). Micropatterning of polymer thin films with ph-sensitive and cross-linkable hydrogen-bonded polyelectrolyte multilayers. Journal of the American Chemical Society, 124(10), 2100-2101. http://dx.doi. org/10.1021/ja017681y. PMid:11878948.

6. Odian, G. G. (2004). Principles of polymerization. Hoboken: John Wiley-Interscience. http://dx.doi.org/10.1002/047147875X.

7. Huang, J., \& Kaner, R. B. (2004). A general chemical route to polyaniline nanofibers. Journal of the American Chemical Society, 126(3), 851-855. http://dx.doi.org/10.1021/ja0371754. PMid: 14733560.

8. Zhang, X., Chan-Yu-King, R., Jose, A., \& Manohar, S. K. (2004). Nanofibers of polyaniline synthesized by interfacial polymerization. Synthetic Metals, 145(1), 23-29. http://dx.doi. org/10.1016/j.synthmet.2004.03.012.

9. Medeiros, E. S., Agnelli, J. A. M., Joseph, K., Carvalho, L. H., \& Mattoso, L. H. C. (2003). Curing behavior of a novolac-type phenolic resin analyzed by differential scanning calorimetry. Journal of Applied Polymer Science, 90(6), 1678-1682. http:// dx.doi.org/10.1002/app.12838.

10. Medeiros, E. S. (2006). Desenvolvimento de sensores de polímeros condutores para avaliação de sucos de laranja (Tese de doutorado). Universidade Federal de São Carlos, São Carlos.
11. Raghunathan, A., Kahol, P. K., \& McCormick, B. J. (1999). Electron localization studies of alkoxy polyanilines. Synthetic Metals, 100(2), 205-216. http://dx.doi.org/10.1016/S03796779(99)00008-9.

12. Paterno, L. G., \& Mattoso, L. H. C. (2001). Effect of pH on the preparation of self-assembled films of poly(o-ethoxyaniline) and sulfonated lignin. Polymer, 42(12), 5239-52452. http:// dx.doi.org/10.1016/S0032-3861(01)00005-2.

13. Costa, L., Montelera, L. R., Camino, G., Weil, E. D., \& Pearce, E. M. (1997). Structure-charring relationship in phenol-formaldehyde type resins. Polymer Degradation \& Stability, 56(1), 23-35. http://dx.doi.org/10.1016/S01413910(96)00171-1.

14. Manfredi, L. B., Osa, O., Fernández, N. G., \& Vázquez, A. (1999). Structure-properties relationship for resols with different formaldehyde/phenol molar ratio. Polymer, 40(13), 3867-3875. http://dx.doi.org/10.1016/S0032-3861(98)00615-6.

15. Stoye, D., \& Freitag, W. (1996). Resins for coatings. Munich: Hanser Publishers.

16. Silverstein, R. M., Bassler, G. C., \& Morrill, T. C. (1976). Identificação espectrométrica de compostos orgânicos. Rio de Janeiro: Guanabara Dois.

17. Zhang, X., \& Salomon, D. H. (1998). The chemistry of novolac resins: 9. Reaction pathways studied via model systems of ortho-hydroxybenzylamine intermediates and phenols. Polymer, 39(24), 6153-6162. http://dx.doi.org/10.1016/S00323861(98)00108-6.

18. Rubner, M. F. (2003).pH controlled fabrication of polyelectrolyte multilayers: assembly and applications. In G. Decher \& J. B. Schlenoff (Eds.). Weinheim: Wiley.

19. Igreja, R., \& Dias, C. J. (2004). Analytical evaluation of the interdigital electrodes capacitance for a multi-layered structure. Sensors and Actuators. A, Physical, 112(2), 291-301. http:// dx.doi.org/10.1016/j.sna.2004.01.040.

Enviado: Jun. 17, 2014

Revisado: Set. 14, 2014 Aceito: Fev. 13, 2015 